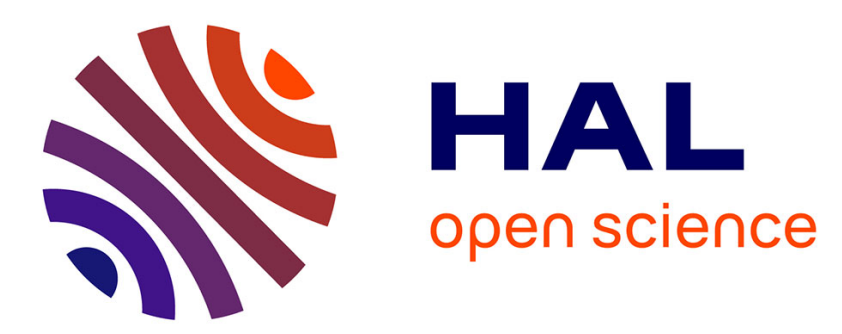

\title{
Structural modifications of WC/Co nanophased and conventional powders processed by selective laser melting
}

\author{
Alexey Domashenkov, András Borbély, Igor Smurov
}

\section{To cite this version:}

Alexey Domashenkov, András Borbély, Igor Smurov. Structural modifications of WC/Co nanophased and conventional powders processed by selective laser melting. Materials and Manufacturing Processes, 2017, 32 (Issue: 1), pp.93-100. 10.1080/10426914.2016.1176195 . emse-01525258

HAL Id: emse-01525258

https://hal-emse.ccsd.cnrs.fr/emse-01525258

Submitted on 27 Aug 2021

HAL is a multi-disciplinary open access archive for the deposit and dissemination of scientific research documents, whether they are published or not. The documents may come from teaching and research institutions in France or abroad, or from public or private research centers.
L'archive ouverte pluridisciplinaire HAL, est destinée au dépôt et à la diffusion de documents scientifiques de niveau recherche, publiés ou non, émanant des établissements d'enseignement et de recherche français ou étrangers, des laboratoires publics ou privés. 


\title{
Structural modifications of WC/Co nanophased and conventional powders processed by selective laser melting
}

\author{
Alexey Domashenkova , András Borbély ${ }^{\mathrm{b}}$, and Igor Smurov ${ }^{\mathrm{a}}$ \\ aLyon University, Ecole Nationale d'Ingénieurs de Saint Etienne, LTDS Laboratory, Saint-Étienne Cedex 2, France; 'byon University, Ecole Nationale \\ Supérieure des Mines, SMS-EMSE, Saint-Etienne, Cedex 2, France
}

\begin{abstract}
Microstructural modifications and mechanical properties of samples manufactured from conventional and nanocomposite WC/Co12 powders by means of Selective laser melting (SLM) are compared after processing with the same parameter set. Studying their homogeneity reveals that in both samples coarse and fine carbides segregate in the molten pool. X-ray diffraction (XRD) analysis shows significant changes in the microstructure and crystalline phases present in the WC/Co mixture and after SLM. Thermal decomposition of WC leads to the formation of $\mathrm{W}_{2} \mathrm{C}$ dicarbides and the appearance of the complex Co-W-C ternary phase. No residual pure cobalt after SLM was detected in the samples. The Williamson-Hall method allows determining coherent WC domain sizes of conventional and nanostructured powders ( $56 \pm 6 \mathrm{~nm}$ and $10 \pm 3 \mathrm{~nm}$, respectively) and microstrains ( $\sim$ for both) as well as their modifications after SLM processing $\left(180 \pm 50 \mathrm{~nm}\right.$ and $2 \cdot 10^{-3} \pm 4 \cdot 10^{-4}$ for the nanophased sample, and $330 \pm 100 \mathrm{~nm}$ and $2 \cdot 10^{-3} \pm 4 \cdot 10^{-4}$ for the conventional one, respectively). The microhardness of the part produced from the nanophased powder is slightly increased in both the coarse $\left(\sim 1496 \mathrm{HV}_{0.3}\right)$ and fine $\left(\sim 1542 \mathrm{HV}_{0.3}\right)$ carbide segregation regions compared to the sample obtained from the conventional powder (1384 $\mathrm{HV}_{0.3}$ and $1515 \mathrm{HV}_{0.3}$ for coarse and fine regions, respectively).
\end{abstract}

\section{Introduction}

Additive manufacturing is a modern approach for the fabrication of demonstrative and functional pieces using a wide range of materials. Selective laser melting (SLM) is a type of additive manufacturing technique implying layer-by-layer laser fusing of the initial powders. This technology allows the fabricating of parts of complex shape with mechanical properties equivalent to or even better than the ones obtained by conventional processing [1-5]. SLM of steels, Co, Ni, Ti-based alloys and some other materials is well known. However, ceramics and composites pose certain problems to the SLM technology due to their high-temperature behavior during melting and solidification.

A ceramic is an important industrial material because of its high thermal resistance and static strength. Nevertheless, the use of ceramics in SLM is a quite complex task, as ceramic processing presumes a tight control of the heating and cooling rates, which cannot be guaranteed during SLM. Hagedorn et al. [6, 7] have provided a few examples of successful ceramic laser melting. Their method includes preheating of the processing zone to a temperature slightly lower than the melting point of the powder material.

Metal matrix composite (MMC) materials can combine the ductility of a metal binder with the strength of a reinforcing phase. Composite materials based on metallic alloys are typically reinforced with dispersion particles, platelets, short fibers and continuous fibers [8]. Reinforcing the matrix highly increases its mechanical properties, such as Young's modulus, tensile strength, etc. [9]. One of the earliest MMCs, first synthesized in the 1890s and developed for industrial applications already in the 1920s, is tungsten carbide cemented by cobalt. WC/Co represents a super-hard material, which has several primary applications in the tool industry (cutting, drilling, mining equipment, etc.) because of its high wear resistance [10-12]. However, in recent years WC/Co has also found a number of applications in coating deposition technologies (plasma spraying, laser cladding, high-velocity oxygen fuel (HVOF), cold spraying, etc.) [13-16].

Studying the influence of carbide size on the mechanical properties of MMCs, such as hardness and fracture toughness, has evidenced that carbides with nanometer size can enhance the hardness up to $9 \%$ and the fracture toughness up to $50 \%$ [17]. One of the first methods of WC/Co nanocomposite powder fabrication was proposed by McCandlish et al. $[18,19]$ and it includes the mixing of $\mathrm{W}$ and $\mathrm{Co}$ at the molecular level with subsequent thermochemical synthesis.

In the present paper, the SLM technique was applied to fabricate WC/Co samples from traditional coarse-grained and nanocomposite powders. The main question we want to answer is how the initial crystallite size influences the microstructure after SLM and what differences can be expected in terms of mechanical properties. 


\section{Materials and methods}

The nanostructured WC/Co12 powder was provided by MBN Nanomaterials S.P.A, Italy, and was manufactured by highenergy milling. Durum Verschleiss-schutz GMBH, Germany, provided the conventional WC/Col2 cermet powder. The conventional composite was produced by the agglomeration and sintering of WC and Co powders. The granulometrical analysis of both powders was performed on the granulomorphometer ALPAGA 500 NANO (OCCHIO S.A.). Figure 1 shows the particle size distributions of the powders.

The chemical composition of the utilized powders is presented in Table 1.

In both cermet powders particles generally have a spherical form, as evidenced by scanning electron microscopy (SEM) images obtained with the TESCAN Vega 3 microscope (Fig. 2). The manufacturer-declared size of the WC grains in the conventional powder is $2.5 \mu \mathrm{m}$ for $90 \%$ of the grains according to the Fisher Sub Sieve Sizer (FSSS). The SEM analysis, however, revealed the presence of WC grains with micron and submicron sizes in the particles of both composites (Figs. 2 (b), (d)). No information about the WC grain size distribution in the nanocomposite was provided by the manufacturer. However, generally both powder particles and WC grains are much finer in the nanophased powder (Figs. 2(a), (b) versus 2(c), (d)). The declared WC crystallite size in the MBN powder is $20 \mathrm{~nm}$ according to the Scherrer formula.

All SLM experiments were performed with a Phenix PM100 machine equipped with an ytterbium fiber laser (nominal wavelength of $1075 \mathrm{~nm}$ and a spot diameter of $70 \mu \mathrm{m}$ ), giving a maximum power of $200 \mathrm{~W}$. Stainless steel 304L was used as the building-substrate material and the building chamber was filled with protective nitrogen gas.

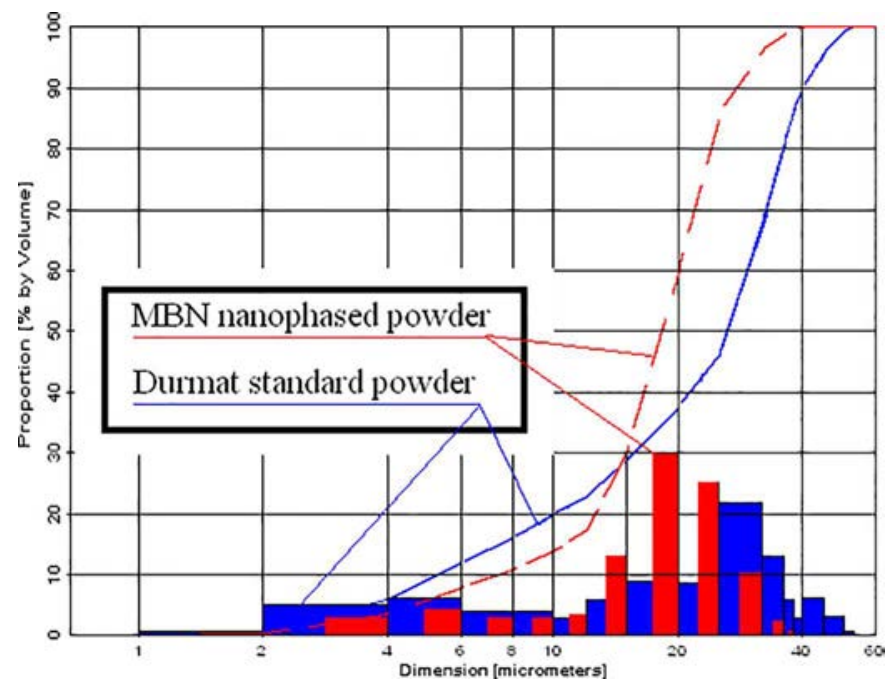

Figure 1. Particle size distributions of the MBN nanostructured and standard Durmat powders.

Table 1. Composition of the initial powders.

\begin{tabular}{lcl}
\hline & Co, \%wt. & WC, \%wt. \\
\hline MBN nanocomposite & $10,5-13,5$ & Bal. \\
Durmat conventional & $11-13$ & Bal. \\
\hline
\end{tabular}

The microhardness tests were performed with BUEHLER Micromet 5104, using a load of $300 \mathrm{~g}$ for all tests. The indention duration was $10 \mathrm{sec}$.

\section{Results and discussion}

\section{SLM process}

Nanocomposites have been already manufactured by SLM [20-24]; however, in all these works the composite powder was obtained by mechanical mixing, while in the present case each powder particle is a nanophased cermet composite. The SLM parametric analysis $[3,25]$ of the MBN nanostructured powder has shown that the optimal single-track stability is achieved for the following process parameters: laser power $P=40 \mathrm{~W}$, powder bed thickness $h=40 \mu \mathrm{m}$ and scanning speed $V=130 \mathrm{~mm} / \mathrm{s}$. This parametric set has evidenced good continuity, absence of distortions, smoother surface morphology and highly reduced number of on-track agglomerates as well as near-track droplets compared with other parameter windows (Fig. 3(a) versus 3(b)).

No signs of cracks were observed in the single tracks, unlike in 3D samples (Fig. 4(a)). This is related to the absence of repeated cycles of heating-cooling and a thermal sink into the substrate, which is typical for the first few layers of a sample, when the processing material is less involved in the absorption of thermal energy.

The three-dimensional samples of $10 \times 10 \times 7 \mathrm{~mm}^{3}$ volume were fabricated with the following parameters: laser power $P=40 \mathrm{~W}$, scanning distance $S=90 \mu \mathrm{m}$, laser speed $V=$ $130 \mathrm{~mm} / \mathrm{s}$ and powder layer thickness $h=40 \mu \mathrm{m}$ (Fig. 3(c)). The crosswise strategy of piece homogenization, turning the laser scans' direction by $90^{\circ}$ after each layer deposition cycle, was applied. The samples from the conventional WC/Co12 powder were produced with the same parameter set. Furthermore, bulk cube-shaped samples from the standard powder are denoted as $S$ samples and from the nanostructured powder as $N$ samples.

\section{Microstructure}

The SEM images show the WC segregated regions in both samples (Fig. 4). No continuous segregation textures were observed, which means that the carbides segregated randomly in the molten pool. The Marangoni convection [26] can influence the in-track segregation of submicron and even microscopic carbides, as the laser spot diameter $(70 \mu \mathrm{m}$ in our case) is comparable with dimensions of the molten pool, which in turn determine the convection rates and consequently the size of the segregated particles.

Cracks in the Co-based matrix were observed for both powders, which are probably induced by the extremely high heating and cooling gradients. One of the solutions for avoiding crack formation in ceramic materials is the in situ temperature control of the piece with a furnace, another laser, etc. $[7,8]$. Presence of an easily fusible matrix in MMCs therefore causes problems for in situ temperature control. As the matrix melting point is relatively low $\left(1495^{\circ} \mathrm{C}\right.$ for cobalt and $2785^{\circ} \mathrm{C}$ for tungsten carbide [27]), the maintained temperature 


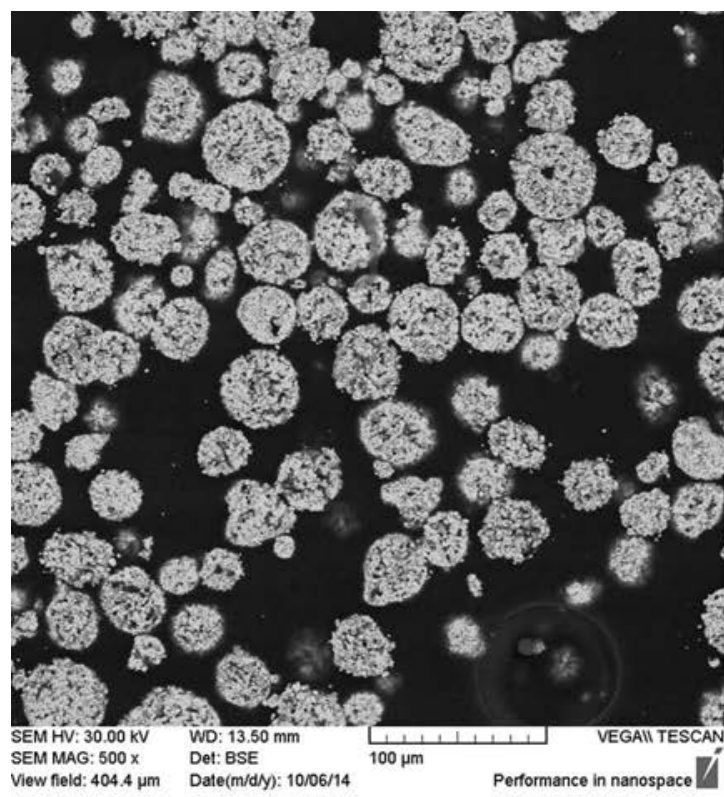

(a)

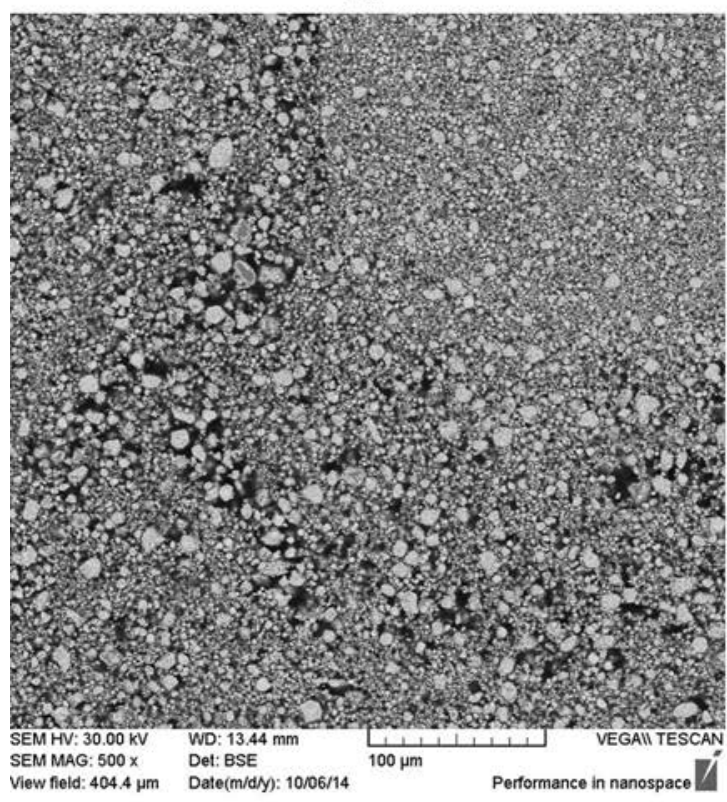

(c)

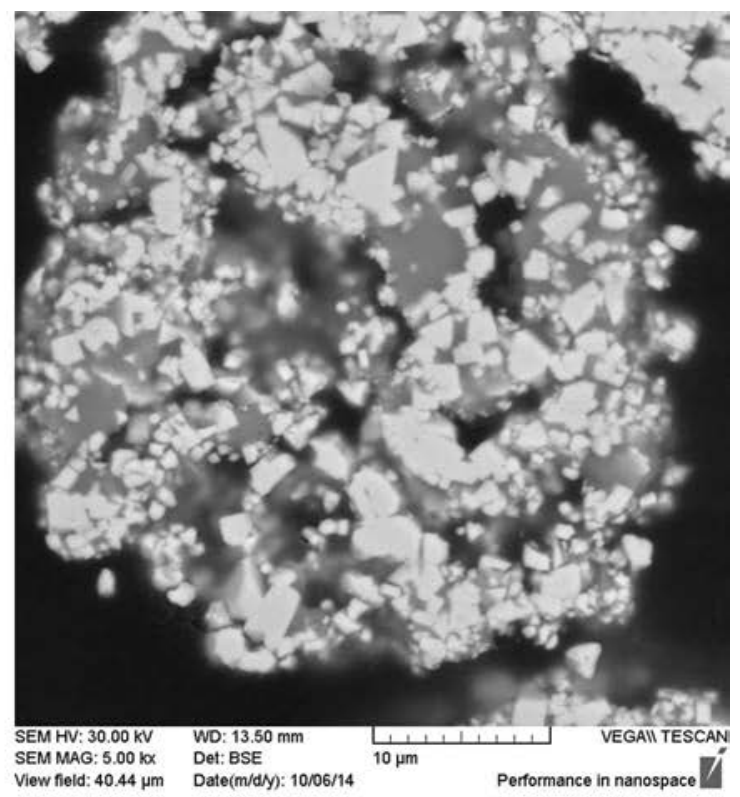

(b)

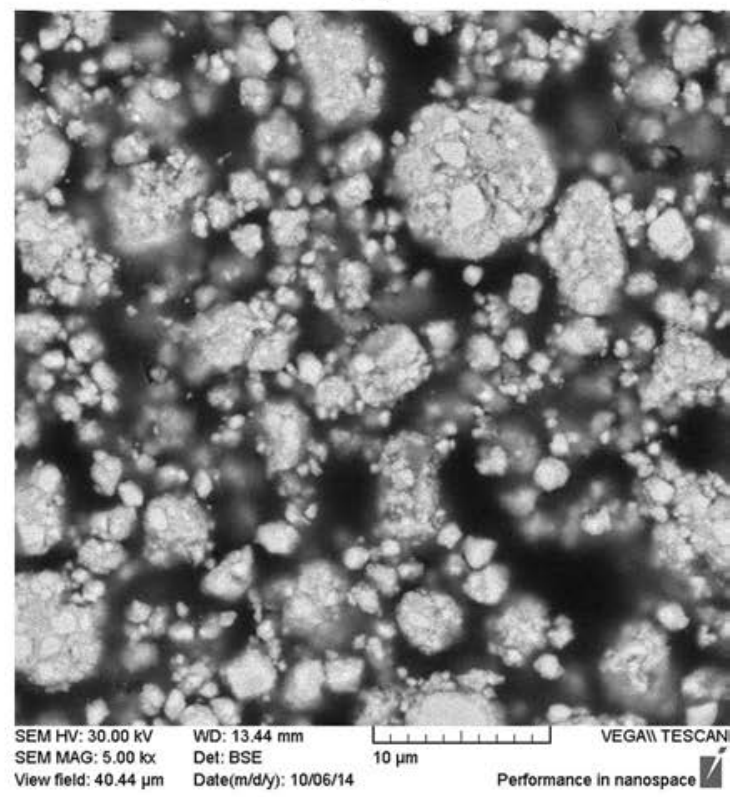

(d)

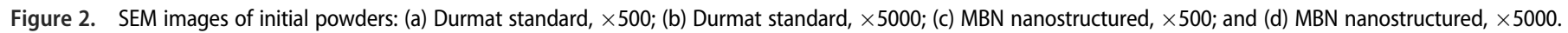

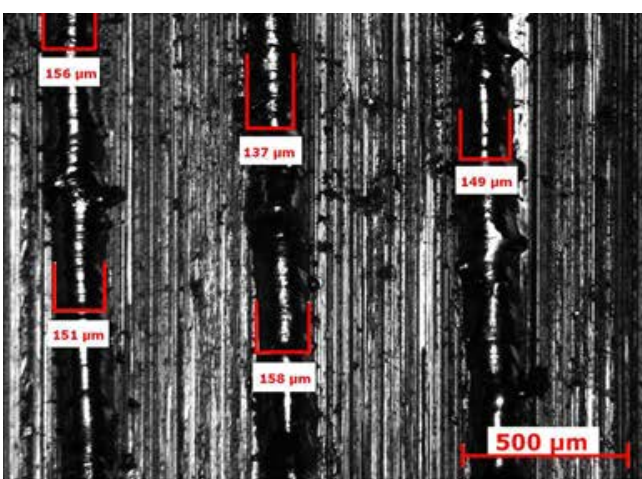

(a)

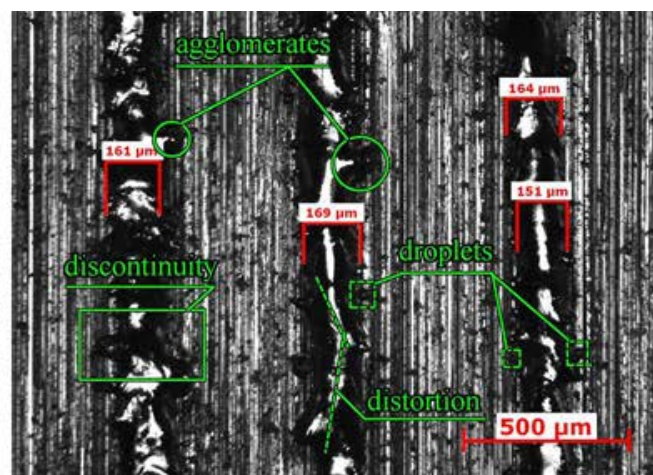

(b)

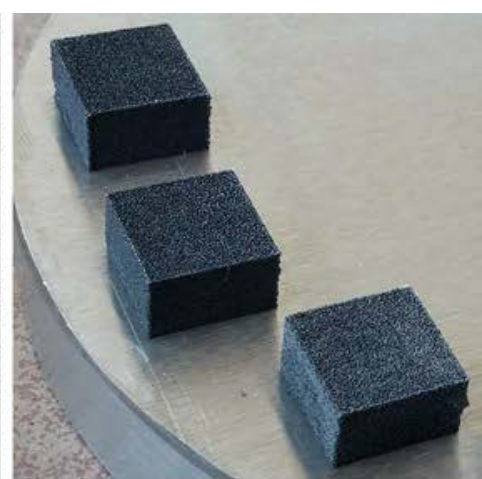

(c)

Figure 3. Single tracks from WC/Co12 nanophased powder: (a) $P=40 \mathrm{~W} ; V=130 \mathrm{~mm} / \mathrm{s}$; high stability; (b) $P=80 \mathrm{~W} ; V=190 \mathrm{~mm} / \mathrm{s}$; low stability; (c) cube-shaped samples manufactured from WC/Co nanostructured powder $P=40 \mathrm{~W}, S=90 \mu \mathrm{m}, V=130 \mathrm{~mm} / \mathrm{s}, h=40 \mu \mathrm{m}$. 


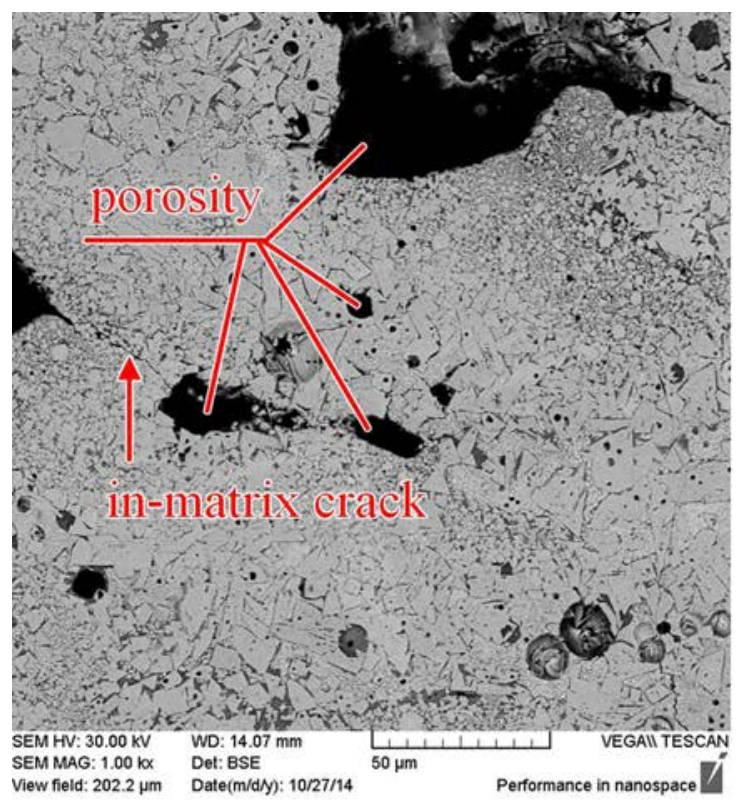

(a)

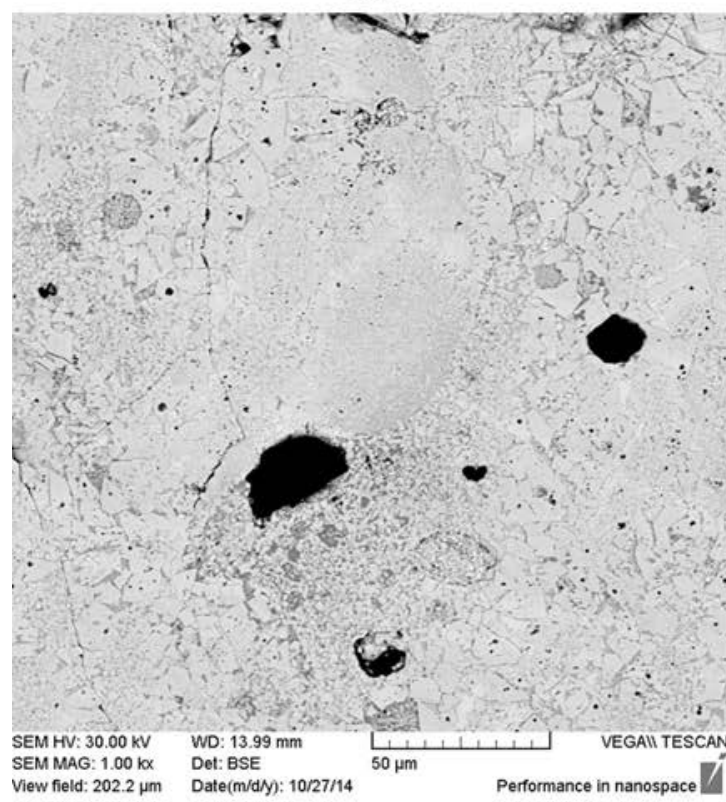

(c)

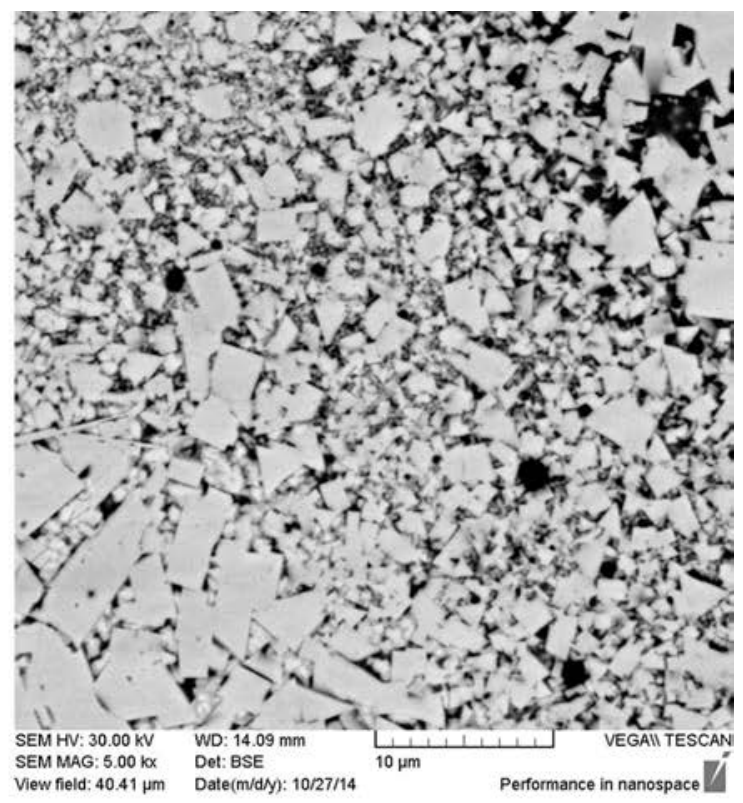

(b)

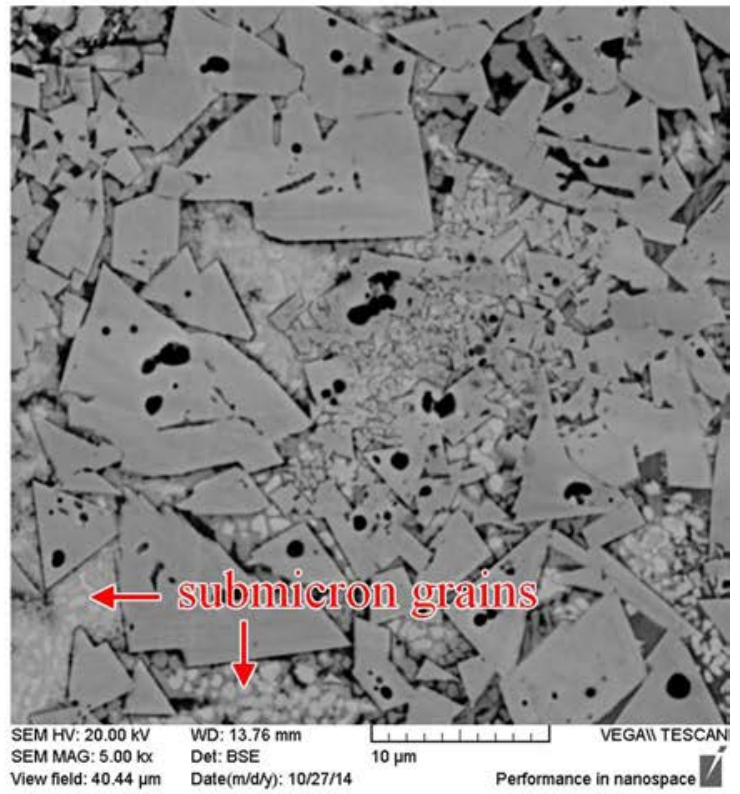

(d)

Figure 4. SEM images of specimens processed identically $(P=40 \mathrm{~W}, S=90 \mu \mathrm{m}, V=130 \mathrm{~mm} / \mathrm{s}, h=40 \mu \mathrm{m})$ : (a) $\mathrm{N}$ sample, $\times 1000$; (b) $\mathrm{N}$ sample, $\times 5000$; (c) $S$ sample, $\times 1000$; (d) S sample, $\times 5000$.

can be insufficient to decrease crack formation probability, but high enough for partial powder sintering before or during a leveling cycle, which can completely interrupt manufacturing.

After laser melting, clearly distinguishable grains with a size of $0.5-2 \mu \mathrm{m}$ were formed in the binder of both samples (Figs. 4 (d) and 5(a)). Electron Dispersive Spectroscopy (EDS) allowed determining the matrix composition and its inhomogeneity after SLM. Tungsten is rather uniformly distributed in the matrix and there is no significant difference between the tungsten content in the matrix and in the carbides (Fig. 5(b)). The so-called thermal decomposition or decarburization process takes place in WC at elevated temperatures [28, 29]. It leads to the formation of $\mathrm{W}_{2} \mathrm{C}$ dicarbides as follows: $2 \mathrm{WC} \rightarrow \mathrm{W}_{2} \mathrm{C}$ $+\mathrm{C}$ [30]. The intensity of this reaction increases with the heating ability of the energy source. The decomposition leads to the decreasing of microhardness (microhardness of the higher WC carbide varies in the range of $18-22 \mathrm{GPa}$, while for the lower carbide $\mathrm{W}_{2} \mathrm{C}$ is between 14.5 and $18.1 \mathrm{GPa}$ [31]). About $\sim 9.5 \%$ of WC cemented by cobalt can be dissolved at $1250^{\circ} \mathrm{C}$ [32].

The $\mathrm{W}_{2} \mathrm{C}$ phase is a strongly nonstoichiometric interstitial compound. There are four known modifications of this carbide: $\beta-\mathrm{W}_{2} \mathrm{C}$ (hexagonal, space group $P 6_{3} / m m c$ ); $\beta^{\prime}-\mathrm{W}_{2} \mathrm{C}$ (orthorhombic, space group $\mathrm{Pbcn}$ ); $\beta^{\prime \prime}-\mathrm{W}_{2} \mathrm{C}$ (rhombohedral, space group $P-3 m 1$ ) and $\varepsilon-\mathrm{W}_{2} \mathrm{C}$ (trigonal, space group $P-31$ $m)$. In all these modifications, tungsten forms similar hexagonal close-packed (hcp) sublattices, where the carbon atoms can occupy $34-52 \%$ of the octahedral interstitial sites. 


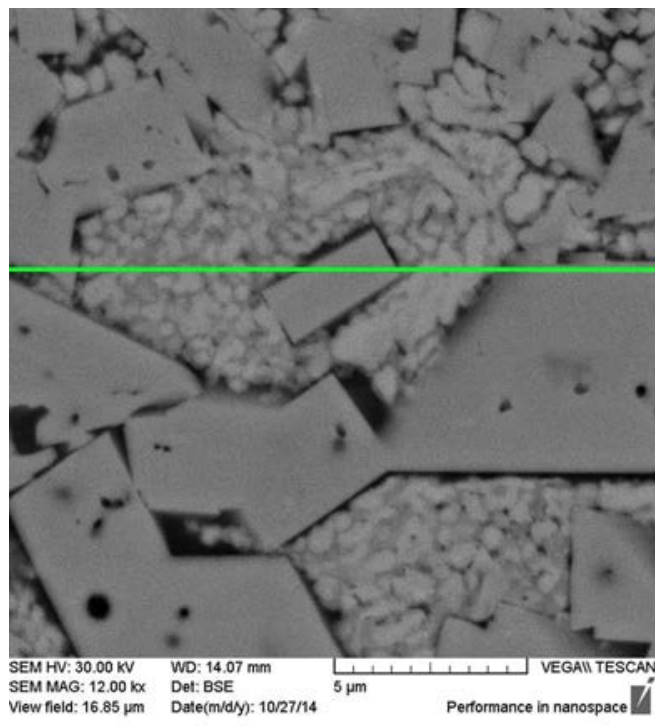

(a)

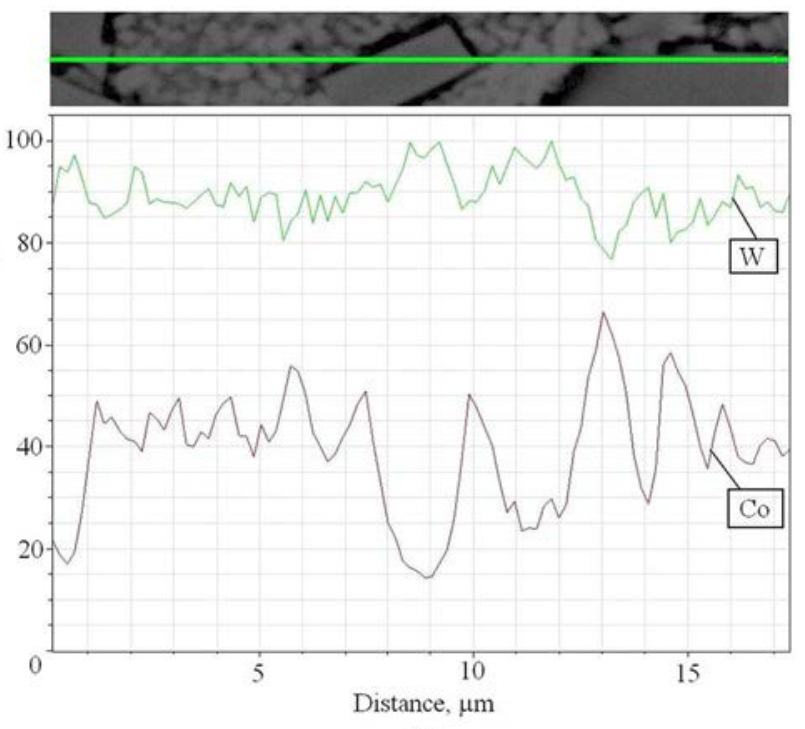

(b)

Figure 5. (a) SEM cross-section of cubic $N$ sample: $P=40 \mathrm{~W}, h=40 \mu \mathrm{m}, V=130 \mathrm{~mm} / \mathrm{s}, S=90 \mu \mathrm{m}$; (b) EDS line scans showing the $\mathrm{W}$ and Co contents.

In XRD experiments, these modifications are almost indiscriminate due to the large difference in the scattering amplitudes of the $\mathrm{W}$ and $\mathrm{C}$ atoms [31].

The eutectoid decomposition of $\mathrm{W}_{2} \mathrm{C}$ to $\mathrm{WC}$ and $\mathrm{W}$ takes place at $\sim 1250^{\circ} \mathrm{C}[33]$. We suggest that a small amount of WC detected by XRD (Fig. 6(b)) belongs to the secondary carbides that appeared after the $\mathrm{W}_{2} \mathrm{C}$ decomposition.

Besides decarburization, carbides and Co can diffuse and form complex carbides such as $\mathrm{W}_{3} \mathrm{Co}_{3} \mathrm{C}, \mathrm{W}_{4} \mathrm{Co}_{2} \mathrm{C}, \mathrm{W}_{6} \mathrm{Co}_{6} \mathrm{C}$

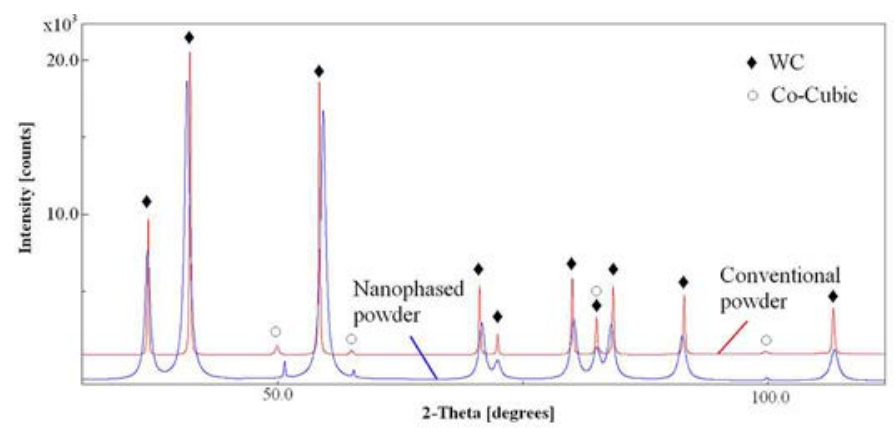

(a)

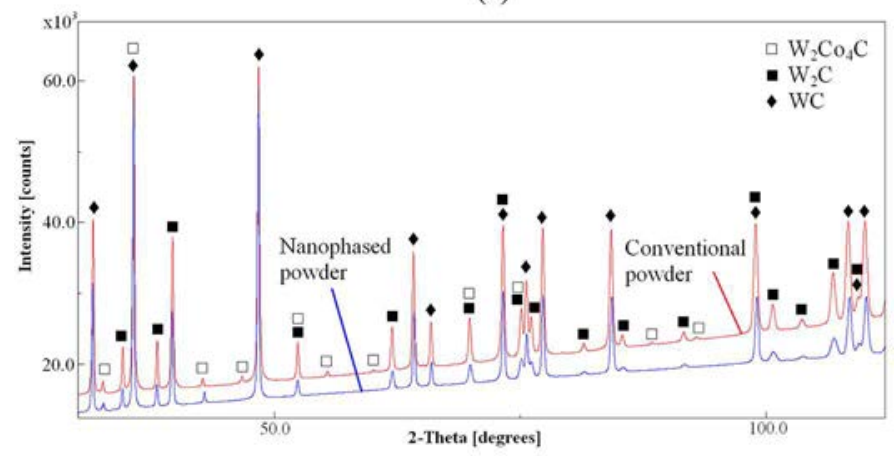

(b)

Figure 6. XRD diffractograms: (a) initial standard and nanophased WC/Co powders; (b) corresponding cubic bulk specimens fabricated by SLM, $P=40 \mathrm{~W}$, $h=40 \mu \mathrm{m}, V=130 \mathrm{~mm} / \mathrm{s}, S=90 \mu \mathrm{m}$. and $\mathrm{W}_{9} \mathrm{Co}_{3} \mathrm{C}_{4}[30,34]$. The presence of the $\mathrm{W}_{2} \mathrm{Co}_{4} \mathrm{C}$ phase, representing $\mathrm{M}_{6} \mathrm{C}$ cubic $\eta$-carbides (space group $F d-3 m$ ), was confirmed by the results of the XRD analysis (Fig. 6(b)). This phase nucleates on the boundaries of WC grains through the interaction with the binder containing Co and some dissolved $\mathrm{W}$ and $\mathrm{C}$. Its nucleation and growth strongly depend on the carbon content in $\mathrm{WC}$ and the content of dissolved $\mathrm{W}$ in the Co matrix $[35,36] . \mathrm{W}_{4} \mathrm{Co}_{2} \mathrm{C}_{\mathrm{y}}$ and $\mathrm{W}_{2} \mathrm{Co}_{4} \mathrm{C}_{\mathrm{y}}$ have very similar crystal structures and differ only in the position of carbon atoms [36], and hence the $\mathrm{W}_{3} \mathrm{Co}_{3} \mathrm{C}_{\mathrm{y}}$ phase often implies these two ternary carbides [31]. In fact, the $\mathrm{W}_{3} \mathrm{Co}_{3} \mathrm{C}_{\mathrm{y}}$ phase is a pseudo-binary solid solution of these carbides. When the carbon content is deficient, this phase corresponds to $\mathrm{W}_{6} \mathrm{Co}_{6} \mathrm{C}_{\mathrm{y}}\left(\mathrm{M}_{12} \mathrm{C}\right)$ [31].

Mari et al. [37] reported that during heat treatment the $\mathrm{W}_{3} \mathrm{Co}_{3} \mathrm{C}$ phase is only present at high temperatures, while $\mathrm{W}_{6} \mathrm{Co}_{6} \mathrm{C}$ appears after sufficient cooling, indicating the metastable nature of the $\mathrm{M}_{6} \mathrm{C}$ phase. Thiele et al. [38] measured the evolution of the $\mathrm{M}_{6} \mathrm{C}$ and $\mathrm{M}_{12} \mathrm{C}$ contents before and after heat treatment of the coating obtained with the HVOF process. It was shown that the mass concentrations of $\mathrm{W}_{6} \mathrm{Co}_{6} \mathrm{C}$ and $\mathrm{W}_{3} \mathrm{Co}_{3} \mathrm{C}$ changed from $14.2 \%$ and $5.6 \%$ to $19.4 \%$ and $3.6 \%$, respectively, after treatment at $1250^{\circ} \mathrm{C}$ for 5 min under a pressure of $30 \mathrm{MPa}$. This suggests that the formation of these carbides occurs at relatively low temperatures.

XRD revealed the presence of a face centered cubic (fcc) Co phase in both initial powders (Fig. 6(a)). After SLM both $N$ and $S$ samples had no residual pure Co phase in their structure. The repeated heating-cooling cycling led to the transformation of all available Co into the $\mathrm{W}_{2} \mathrm{Co}_{4} \mathrm{C}$ phase.

According to the $\mathrm{XRD}$ results, the specific surface area of WC grains in the feedstock powder does not affect the phase composition after laser melting. The results of the Rietveld analysis are presented in Table 2. All available cobalt has absorbed tungsten and carbon and finally transformed into the $\mathrm{W}_{2} \mathrm{Co}_{4} \mathrm{C}$ compound. We also suggest that some Co was evaporated during laser treatment with the applied parameters. 
Table 2. Phase quantification results according to the Rietveld analysis.

\begin{tabular}{lccc}
\hline & $\mathrm{WC}, \%$ & $\mathrm{~W}_{2} \mathrm{C}, \%$ & $\mathrm{~W}_{2} \mathrm{Co}_{4} \mathrm{C}, \%$ \\
\hline$N$ sample & 75 & 22 & 3 \\
$S$ sample & 76 & 21 & 3 \\
\hline
\end{tabular}

\section{WC crystallite analysis}

Usually crystallite size is determined from the Full Width at Half Maximum (FWHM) of XRD peaks using the Scherrer equation. This is however applicable only in cases when micro-strain is vanishing, i.e., the width of peaks $(\Delta K)$ in the reciprocal space ( $\mathrm{K}$-space) is constant. According to our analysis, this condition is fulfilled only by the initial WC powders, whereas after SLM the WC crystallites exhibit significant microstrain. Thus, the Williamson-Hall plot [39] was used to obtain the diffraction order independent part of the broadening. The method is based on the following equation linking the broadening $\Delta K$ to the coherent domain size $D$, and the microstrain $\varepsilon$ :

$$
\Delta K=\frac{k_{S c h}}{D}+\varepsilon K,
$$

where $k_{s c h}$ is the Scherrer constant, which depends on the crystallite shape, for cube-shaped grains $k_{S c h}=0.9$ and $K$ is the scattering vector, defined as

$$
K=\frac{2 \sin \theta}{\lambda},
$$

where $\lambda$ is the wavelength and $\theta$ is half of the scattering angle. Figure 7 shows the Williamson-Hall plots for the initial powders and the manufactured bulk samples. The graphs indicate that the initial powders are free of microstrain, while the WC particles in the manufactured bulk samples are subjected to microstrains. The numerical values for the crystallite sizes and for the microstrains are shown in Table 3. Interestingly, there are no large differences between the microstructures of the bulk samples in terms of these parameters. It should be noted that the crystallite size obtained from the Williamson-Hall method is not equivalent to the grain or particle size. According to references $[40,41] \mathrm{WC}$ particles larger than $2.5-4 \mu \mathrm{m}$ are usually made up of several grains. The crystallite size determined from $\mathrm{XRD}$ is smaller than these and can be identified with the subgrain size [42], so that one grain may contain several crystallites/subgrains.

Park et al. [43] studied samples manufactured by die pressing from conventional and nanostructured WC/Co powders. Although optical and electron microscopy images showed no signs of a grain distinction, the comparative XRD diffractograms revealed the presence of nanoscaled crystallites in WC grains. However, they did not found a significant difference between the crystallite sizes in nanophased $(57 \pm 7 \mathrm{~nm})$ and conventional $(49 \pm 9 \mathrm{~nm})$ powders. But the WC crystallite area in this work was 6-100 times smaller than the WC grain area, indicating less-perfect crystalline nature of the carbide grains. Increasing the sintering temperature increased proportionally both the crystallite and grain sizes of WC. This suggests that the growth of crystallites during SLM is directly related to the applied effective

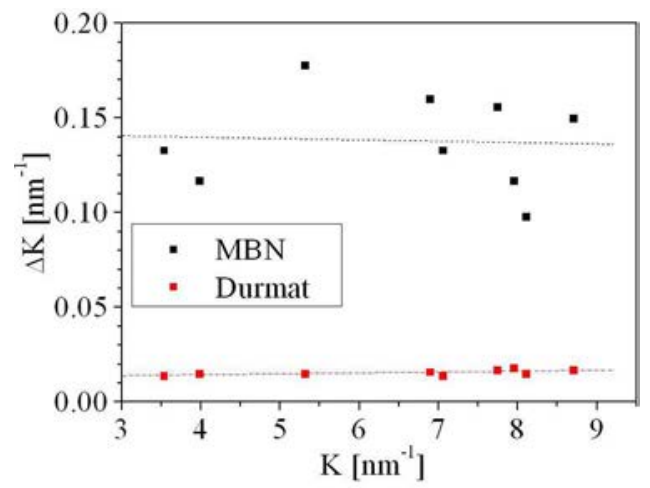

(a)

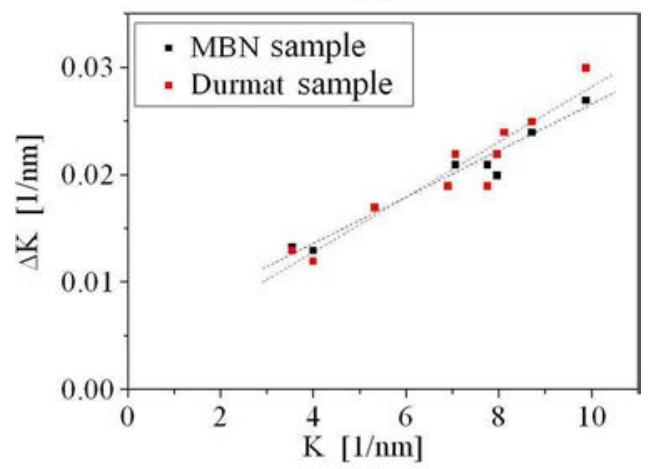

(b)

Figure 7. Williamson-Hall plot of WC peak widths corresponding to: (a) initial nanophased powder (MBN) and conventional powder (Durmat), and (b) $\mathrm{N}$ and $S$ cubic samples processed identically $(P=40 \mathrm{~W}, h=40 \mu \mathrm{m}, V=130 \mathrm{~mm} / \mathrm{s}$, $S=90 \mu \mathrm{m})$.

laser energy. In this case, increasing the laser energy results in a more pronounced growth of WC crystallites. Thus in order to increase the strength properties, it is preferable to apply low-energy parametric windows to manufacture a piece part (without taking into account other effects such as rates of decarburization, binder evaporation and phase transformations, residual stresses, etc.).

SLM usually produces parts with quite high residual stresses due to the extreme heating and cooling rates [44]. For the same reason many crystal defects may be produced during solidification. That is why $\mu$-strain develops in bulk samples, which interestingly is identical in both samples and independent of the initial crystallite size. To understand the origin of the $\mu$-strains, the dislocation model of strain broadening as proposed by Ungár et al. [45] was tested with the current data. Using the isotropic contrast factors of dislocations and the modified Williamson-Hall plot [45], the scatter of peak widths on Fig. 7(b) could not be reduced, which means that the origin of $\mu$-strain is linked to other lattice defects in the present case.

Table 3. Results of the Williamson-Hall analysis for crystallite sizes and $\mu$-strains.

\begin{tabular}{lcc}
\hline Sample & Domain size, $\mathrm{nm}$ & $\mu$-strain \\
\hline MBN nanophased powder & $10 \pm 3$ & 0 \\
Durmat conventional powder & $56 \pm 6$ & 0 \\
Bulk sample made of MBN & $180 \pm 50$ & $2 \cdot 10^{-3} \pm 4 \cdot 10^{-4}$ \\
Bulk sample made of Durmat & $330 \pm 100$ & $2 \cdot 10^{-3} \pm 4 \cdot 10^{-4}$ \\
\hline
\end{tabular}




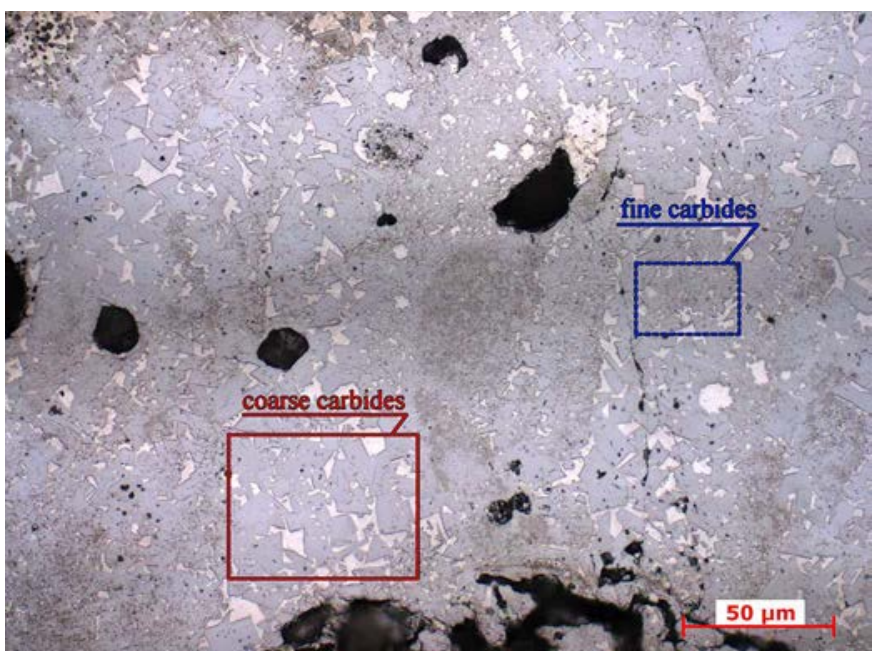

Figure 8. Structure of the specimen obtained from the standard WC/Co12 powder. Regions of coarse and fine carbides for microhardness tests.

Table 4. Microhardness test results.

\begin{tabular}{lcccc}
$\begin{array}{l}\text { Microhardness, } \\
\mathrm{HV}_{0.3}\end{array}$ & $\begin{array}{c}\text { Coarse carbide } \\
\text { regions in } \\
\text { the } N \text { sample }\end{array}$ & $\begin{array}{c}\text { Fine carbide } \\
\text { regions in } \\
\text { the } N \text { sample }\end{array}$ & $\begin{array}{c}\text { Coarse carbide } \\
\text { regions in } \\
\text { the } S \text { sample }\end{array}$ & $\begin{array}{c}\text { Fine carbide } \\
\text { regions in } \\
\text { the S sample }\end{array}$ \\
Average & 1496 & 1542 & 1384 & 1515 \\
Min. & 1400 & 1429 & 1053 & 1153 \\
Max. & 1588 & 1697 & 1588 & 1660 \\
\hline
\end{tabular}

\section{Microhardness}

Due to carbide segregation in the Co-based binder the microhardness measurements were performed as follows: in both $S$ and $N$ samples 10 regions with coarse and 10 regions with fine carbide segregation were selected. Each region was free of porosity and cracks (Fig. 8). Owing to the small amount of the binder phase there are no vast segregation regions, i.e., coarse and fine carbides segregated in zones with typical sizes of a few tens of microns (Fig. 8).

It is known [17] that not only the size of carbide particles determines the hardness in MMCs, but also the strength behavior of the binder phase after processing. For WC/Co cermets the fraction of the Co-based matrix and its mean free path of dislocations strongly determine the resulting hardness. Decreasing both factors increases the hardness [46]. In both coarse and fine carbide regions the mean value of microhardness is higher for the nanophased powder than that for the conventional one (Table 4). The difference in the microhardness between the coarse and fine regions is two times lower for the $N$ sample, which indicates an increased homogeneity compared to the $S$ sample.

\section{Conclusions}

- The unstable thermal cycling during SLM impedes obtaining 100\% densification and avoiding of cracks.

- Coarse and fine carbide segregation regions with typical sizes of a few tens of microns were observed. The variations of the binder phase fraction and the carbide size in these regions determine the homogeneity of the samples.
- The comparative XRD analysis of the samples from the standard and nanophased WC/Co12 powders revealed structural modifications of WC and the binder phase. The WC decarburization led to the complete transformation of pure Co matrix into the ternary $\mathrm{Co}_{4} \mathrm{~W}_{2} \mathrm{C}$ compound. In spite of the difference in the initial WC grain size, the synthetized bulk samples have nearly identical microstructures.

- WC crystallite size growth is caused in both cases by repeated thermal cycling, when each laser pass heats few previously deposited layers. According to the Williamson-Hall method the resulting WC crystallite size depends on the initial one. In the sample prepared from the nanostructured powder, the size of WC crystallites increased from $10 \pm 3 \mathrm{~nm}$ to $180 \pm 50 \mathrm{~nm}$, and in the conventional sample from $56 \pm 6$ $\mathrm{nm}$ to $330 \pm 100 \mathrm{~nm}$. No microstrain was detected in the WC grains of the initial powders, while the measured $\mu$-strains after SLM were about $2 \cdot 10^{-3}$ for both samples.

- The microhardness test revealed the increased homogeneity in the mechanical properties of the sample made from the nanophased powder. The average microhardness was $\sim 1496 \mathrm{HV}_{0.3}$ in the coarse carbide segregation regions of the nanophased sample and $\sim 1542 \mathrm{HV}_{0.3}$ in the fine carbide segregation regions. For the standard sample the measured values were $\sim 1384$ HV0.3 and $\sim 1515$ HV0.3 for coarse and fine regions, respectively.

\section{Acknowledgments}

The authors acknowledge the help of Huguette Bruyas from the X-ray laboratory of EMSE.

\section{References}

[1] Simonelli, M.; Tse, Y.Y.; Tuck, C. Effect of the build orientation on the mechanical properties and fracture modes of SLM Ti-6Al-4 V. Materials Science and Engineering: A 2014, 616, 1-11.

[2] Leuders, S.; et al. On the mechanical behaviour of titanium alloy TiAl6V4 manufactured by selective laser melting: Fatigue resistance and crack growth performance. International Journal of Fatigue 2013, 48, 300-307.

[3] Mertens, A.; et al. Mechanical properties of alloy Ti-6Al-4 V and of stainless steel 316L processed by selective laser melting: Influence of out-of-equilibrium microstructures. Powder Metallurgy 2014, 57 (3), 184-189.

[4] Murr, L.E.; et al. Microstructure and mechanical behavior of Ti-6Al-4 $\mathrm{V}$ produced by rapid-layer manufacturing, for biomedical applications. Journal of the mechanical behavior of biomedical materials 2009, 2 (1), 20-32.

[5] Prashanth, K.G.; et al. Microstructure and mechanical properties of Al-12Si produced by selective laser melting: Effect of heat treatment. Materials Science and Engineering: A 2014, 590, 153-160.

[6] Yves-Christian, H.; et al. Net shaped high performance oxide ceramic parts by selective laser melting. Physics Procedia 2010, 5, 587-594.

[7] Wilkes, J.; et al. Additive manufacturing of $\mathrm{ZrO}_{2}-\mathrm{Al}_{2} \mathrm{O}_{3}$ ceramic components by selective laser melting. Rapid Prototyping Journal 2013, 19 (1), 51-57.

[8] Kaczmar, J.W.; Pietrzak, K.; Włosiński, W. The production and application of metal matrix composite materials. Journal of Materials Processing Technology 2000, 106 (1), 58-67.

[9] Doel, T.J.A.; Bowen, P. Tensile properties of particulate-reinforced metal matrix composites. Composites Part A: Applied Science and Manufacturing 1996, 27 (8), 655-665. 
[10] Childs, T.; Maekawa, K.; Obikawa, T.; Yamane, Y. Metal Machining: Theory and Application; Butterworth-Heinemann: Oxford, England, 2000.

[11] Larsen-Basse, J. Effect of composition, microstructure, and service conditions on the wear of cemented carbides. JOM 1983, 35 (11), $35-42$.

[12] Shetty, D.K.; et al. Indentation fracture of WC-Co cermets. Journal of Materials Science 1985, 20 (5), 1873-1882.

[13] Afzal, M.; Ajmal, M.; Nusair Khan, A. Wear behavior of WC-12\% Co coatings produced by air plasma spraying at different standoff distances. Tribology Transactions 2014, 57 (1), 94-103.

[14] Yang, T.; et al. Microstructure evolution of thermal spray WC-Co interlayer during hot filament chemical vapor deposition of diamond thin films. Journal of Alloys and Compounds 2015, 639, 659-668.

[15] Wang, H-T.; et al. Microstructure and properties of cold sprayed multimodal WC-17Co deposits. International Journal of Refractory Metals and Hard Materials 2014, 45, 196-203.

[16] Ma, N.; et al. Improvement on mechanical properties and wear resistance of HVOF sprayed WC-12Co coatings by optimizing feedstock structure. Applied Surface Science 2014, 320, 364-371.

[17] Chivavibul, P.; et al. Effects of carbide size and Co content on the microstructure and mechanical properties of HVOF-sprayed WC-Co coatings. Surface and Coatings Technology 2007, 202 (3), 509-521.

[18] McCandlish, L.E.; Kear, B.H.; Kim, B.K. Chemical processing of nanophase WC-Co composite powders. Materials Science and Technology 1990, 6 (10), 953-957.

[19] McCandlish, L.E.; Kear, B.H.; Bhatia, S. Spray Conversion Process for the Production of Nanophase Composite Powders. European patent office, EP0452480 A1, 1991.

[20] Gu, D.; Guoquan, Z. Selective laser melting of novel nanocomposites parts with enhanced tribological performance: Nanocrystalline TiC/ Ti nanocomposites parts were built via SLM technology and the densification, microstructures, microhardness and tribological performance were investigated. Virtual and Physical Prototyping 2013, 8 (1), 11-18.

[21] Wei, Q.; et al. 2015. Selective laser melting of stainless-steel/nanohydroxyapatite composites for medical applications: Microstructure, element distribution, crack and mechanical properties. Journal of Materials Processing Technology 2015, 222, 444-453.

[22] Gu, D.; et al. 2015. Densification behavior, microstructure evolution, and wear property of $\mathrm{TiC}$ nanoparticle reinforced AlSi10Mg bulkform nanocomposites prepared by selective laser melting. Journal of Laser Applications 2015, 27 (S1), S17003.

[23] Song, B.; Dong, S.; Coddet, C. Rapid in situ fabrication of Fe/SiC bulk nanocomposites by selective laser melting directly from a mixed powder of microsized Fe and SiC. Scripta Materialia 2014, 75, 90-93.

[24] Gu, D.; et al. Selective laser melting additive manufacturing of TiC/ AlSi10Mg bulk-form nanocomposites with tailored microstructures and properties. Physics Procedia 2014, 56, 108-116.

[25] Yadroitsev, I.; Bertrand, Ph.; Smurov, I. Parametric analysis of the selective laser melting process. Applied surface science 2007, 253 (19), 8064-8069.

[26] Rombouts, M.; et al. Fundamentals of selective laser melting of alloyed steel powders. CIRP Annals-Manufacturing Technology 2006, 55 (1), 187-192.
[27] Haynes, W. M.; Lide, D. R.; Bruno, T. J.; Eds. CRC Handbook of Chemistry and Physics. CRC Press: Boca Raton, FL, 2014., 2014.

[28] Sara, R.V. Phase Equilibria in the system tungsten-carbon. Journal of the American Ceramic Society 1965, 48 (5), 251-257.

[29] Kear, B.H.; Skandan, G.; Sadangi, R.K. Factors controlling decarburization in HVOF sprayed nano-WC/Co hardcoatings. Scripta Materialia 2001, 44 (8), 1703-1707.

[30] Li, C-J.; Ohmori, A.; Harada, Y. Effect of powder structure on the structure of thermally sprayed WC-Co coatings. Journal of materials science 1996, 31 (3), 785-794.

[31] Kurlov, A.; Gusev, A. Tungsten Carbides: Structure, Properties and Application in Hardmetals. Springer International Publishing: Cham, Switzerland, 2013.

[32] Wirmark, G.; Dunlop, G.L. Phase transformations in the binder phase of Co-WC cemented carbides. Science of hard materials. Springer US, 1983, 311-28.

[33] Rudy, E.; Windisch, S. Evidence for Zeta Fe2N-Type sublattice order in $\mathrm{W} 2 \mathrm{C}$ at intermediate temperatures. Journal of the American Ceramic Society 1967, 50 (5), 272-273.

[34] Zhan, Q.; et al. 2012. Quantitative evaluation of the decarburization and microstructure evolution of WC-Co during plasma spraying. Surface and Coatings Technology 2012, 206 (19), 4068-4074.

[35] Pollock, C.B.; Stadelmaier, H.H. The eta carbides in the Fe-W-C and $\mathrm{Co}-\mathrm{W}-\mathrm{C}$ systems. Metallurgical Transactions 1970, 1 (4), 767-770.

[36] Skogsmo, J.; Norden, H. The formation of $n$-phase in cemented carbides during chemical vapour deposition. International Journal of Refractory Metals and Hard Materials 1992, 11 (1), 49-61.

[37] Mari, D.; Berger, L.M.; Stahr, S. Analysis of microstructural changes with temperature of thermally sprayed WC-Co coatings by mechanical spectroscopy. Solid State Phenomena. Vol. 184. Trans Tech Publications, 2012.

[38] Thiele, S.; et al. Thermophysical and microstructural studies on thermally sprayed tungsten carbide-cobalt coatings. Journal of Thermal Spray Technology 20 (1-2), 358-365.

[39] Williamson, G.K.; Hall, W.H. X-ray line broadening from filed aluminium and wolfram. Acta metallurgica 1953, 1 (1), 22-31.

[40] Lassner, E.; Schubert, W-D. Tungsten: Properties, Chemistry, Technology of the Element, Alloys, and Chemical Compounds; Kluwer Academic/Plenum: New York, 2012.

[41] Upadhyaya, G.S. Tungsten Properties, Chemistry, Technology of the Element, Alloys, and Chemical Compounds; Noyes Publications: Westwood, NJ, 1998.

[42] Ungár, T.; et al. Crystallite size distribution and dislocation structure determined by diffraction profile analysis: Principles and practical application to cubic and hexagonal crystals. Journal of Applied Crystallography 2001, 34 (3), 298-310.

[43] Park, S.J.; et al. Grain size measurement methods and models for nanograined WC-Co. International Journal of Refractory Metals and Hard Materials 2008, 26 (3), 152-163.

[44] Shiomi, M.; et al. 2004. Residual stress within metallic model made by selective laser melting process. CIRP Annals-Manufacturing Technology 2004, 53 (1), 195-198.

[45] Ungár, T.; et al. Particle-size, size distribution and dislocations in nanocrystalline tungsten-carbide. Nanostructured Materials 1999, 11 (1), 103-113.

[46] Lee, H-C.; Gurland, J. Hardness and deformation of cemented tungsten carbide. Materials Science and Engineering 1978, 33 (1), 125-133. 